International Review of Research in Open and Distributed Learning Volume 18, Number 1

February - 2017

\title{
The Effects of Integrating Social Learning Environment with Online Learning
}

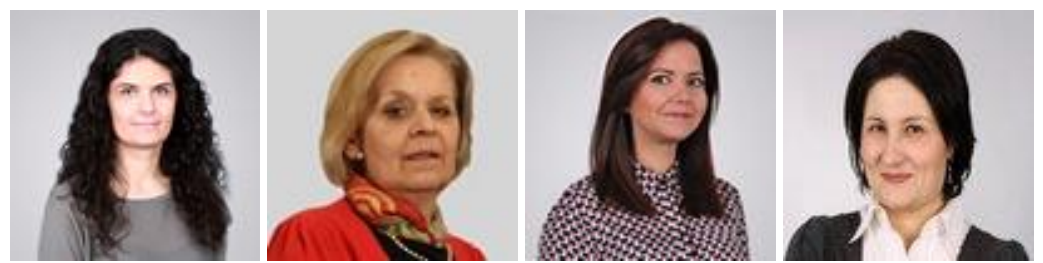

Miroslava Raspopovic, Svetlana Cvetanovic, Ivana Medan, and Danijela Ljubojevic Belgrade Metropolitan University, Serbia

\begin{abstract}
The aim of this paper is to present the learning and teaching styles using the Social Learning Environment (SLE), which was developed based on the computer supported collaborative learning approach. To avoid burdening learners with multiple platforms and tools, SLE was designed and developed in order to integrate existing systems, institutional learning, management systems, and Facebook. With SLE, a learner is exposed to instructional learning material, problem-based, project-based, and social learning. This work focuses on presenting and analyzing effectiveness of implemented teaching and learning scenarios that are used by means of SLE. This study investigates the use of SLE as a learning environment and it examines student satisfaction and online activity while using it. The aim is to evaluate the overall effectiveness of integrating SLE with online learning and to determine how using SLE effects student learning. This analysis points out the advantages and disadvantages of using SLE in online learning and provides recommendations for future improvements.
\end{abstract}

Keywords: social learning environment, online learning, collaborative learning, computer supported collaborative learning approach, interaction

\section{Introduction}

Rapid technological developments have enabled evolution of technologies used for learning. Expansion of numerous tools has diversified educators' options towards the implementation of the technology-supported learning, including a heterogeneous set of tools, such as Learning Management Systems (LMS), virtual classrooms, massive open online courses (MOOCs), and serious games. One of the most important aspect 
of using them is that they provide interaction between students, which leads to better socialization and cooperation online.

The role of interaction in online learning is crucial for effective learning because it is not only studentstudent interaction that matters. Six different forms of interaction that account for learning can be recognized in distance learning education: student-student, student-teacher, student-content, teacherteacher, teacher-content, and content-content (Zornić \& Hasanović, 2011).

Theories that support inclusion of new technologies in the learning process are based on the assumption that students are active participants who seek and construct knowledge within a context that has meaning to them. Communication and collaborative learning can be realized by means of collaborative tools (which are generally an integral part of the learning management system, or can be applied as an application on the network). Although there are many diverse tools, the architecture of a learning system puts a heavy task for e-learning to be integrated into a complex system that is at the same time scalable, flexible, and, most importantly, evolvable and capable of lasting. Using traditional LMS without any external tools, the learning space is left under the control of the institution and instructors. As a result, this leaves little room for learners to arrange their digital learning space, and to facilitate their activities (Väljataga \& Tammets, 2011).

In our work, we propose that a social learning environment (SLE) is used to support not only learning activities from the institutional e-learning system, but also problem solving, collaboration, and communication with instructor and their peers. SLE is based on the computer supported collaborative learning (CSCL) approach (Koschmann, 1996; Wang, 2009), focusing on the user experience and behavior similar to social networks. Social networks and their activities, when used appropriately, can be viewed as a manifestation of informal learning and a platform that allows collaboration and effective communication. Social networks represent a common space where friends can share information that can be viewed by others. Therefore, social networks represent a good candidate to be used as an additional source for learning. Studies have shown that students spend a significant amount of time on social networks, checking and engaging in a variety of activities (Junco, 2012a). Nevertheless, even though social networks have been promoted as one of the ways to increase the interaction and communication between students (McLoughlin \& Lee, 2010), it is necessary to accompany the usage of social networks in learning along with appropriate pedagogical methods. However, the merging of the formal and the informal learning through the use of social networks in higher education still remains a contested topic (Donlan, 2014).

In order to explore and utilize such opportunities, and examine the usefulness of social networks in higher education, it is necessary to build a system that will simulate social network usage by integration of institutional e-learning system with external tools under appropriate constraints and in the controlled learning environment. This paper explores the possibility of using such a system designed on the premises of computer-supported collaborative learning theories and specifically on the basis of the benefits of integrating social networks functionalities of interaction and collaboration in the learning formats. 


\section{Background}

Sociocultural theory and constructivism are rich soil for explaining collaborative learning, the importance of social interaction in online social learning environments and using social networks in online learning. Lev Vygotsky (1987) argued that children learn best in a social environment, and construct meaning through interaction with others. He stated that "with collaboration, direction, or some kind of help the child is always able to do more and solve more difficult tasks that he can independently" (Vygotsky, 1987, p. 2011).

Students can take an active part in the learning process if the classes are organized in a way that supports learning through discovery (discovery learning). This type of learning requires students to independently and inductively draw conclusions, not only to be passive listeners-receptors of the presented material but they must process the problem set before them as part of their cognitive abilities, which leads both to an increase in the quality of knowledge and its durability, and to the development of intellectual abilities.

Eric Mazur's idea on peer instruction is similar to the idea of Bruner's scaffolding (Bruner, 1996). Mazur developed his idea at the beginning of the 9os and has so far supported it by numerous studies (Fagen, Crouch, \& Mazur, 2002). Peer instruction is an interactive strategy in teaching when teachers' lecture is stopped periodically to pose a question (these questions are called ConceptTests). The procedure is as follows:

1. Question posed.

2. Students given time to think.

3. Students record or report individual answers.

4. Neighboring students discuss their answer.

5. Feedback to teacher: Tally of answers.

6. Explanation of the correct answer. (Turpen \& Finkelstein, 2010)

As students are mainly using Facebook for communication and interaction, including adaptation to new school programs and cultures, discovering social activities, finding and maintaining relationships, seeking knowledge on a variety of subjects, self-representation and self-promotion, recruitment, sharing knowledge, academic purposes, and adhering to specific agendas, findings show that using Facebook increases learners' self-efficacy, motivation, and self-esteem while reducing anxiety in the teaching and learning processes (Aydin, 2012).

Through social online interaction and discussion students collaboratively share messages not only relating to their tasks and concerns that they may have about that task, but also their own strategies on how a specific task can be solved/completed. Online learning environment that uses social networking can help establishing online connections and minimize isolation feelings, which usually occur in online learning where students feel isolated or lonely. Establishing these online collections through online learning environment can develop learning communities, which in return develop positive sense contributing to 
student satisfaction (Swan \& Shih, 2005), perceived learning (Richardson \& Swan, 2003), and social presence (Kehrwald, 2008). Christudason concluded from her research that peer learning activities result in: (a) team-building spirit and more supportive relationships; (b) greater psychological well-being, social competence, communication skills, and self-esteem; and (c) higher achievement and greater productivity in terms of enhanced learning outcomes (Christudason, 2003).

Nowadays teachers and students use the social media as important teaching strategy for learning, collaboration, and participation (Dabbagh \& Kitsantas, 2012). There have been various interests in integrating the social media in the learning process (Lewis, Pea, \& Rosen, 2010), while there is evidence that such approach can be effective, there are also some negative implications (Kreijns, Kirschner, \& Jochems, 2003). Moreover, Roblyer, McDaniel, Webb, Herman, and Witty (2010) found that students are more prone to use social networks and similar technologies in learning, than their faculty who prefer traditional methods. Similarly, Tess (2013) reported that universities are not proactive and agile in introducing social media in their teaching, even though they have sufficient infrastructure and support.

However, the way technology is used is more important in predicting students' performance than the time spent on the technology (Wenglinsky, 2005). The inclusion of technology in teaching does not automatically result in effective teaching practices and deep meaningful learning unless effective pedagogical use of the technology is practiced. Technology should be regarded as enabler and not the driver.

Different learning styles have been implemented in classrooms and have been shown effective for online learning as well, including design-based learning (Joordens, Chandrasekaran, Stojcevski, \& Littlefair, 2012). Design-based learning combines both problem-based and project-based learning. Problem-based learning is based on the instructional method used to initiate students' learning, motivation, and acquisition of content knowledge, problem solving, and self-directed learning skills. This approach focuses on facilitating the learning process, and not as much on providing the knowledge in the instructional form (Kolmos, 1996). Project-based learning is perceived to be a student-centered approach, with the goal for the learner to take the ownership of the learning through the problem solving process (Savery \& Duffy, 1995).

If we think of nowadays learners that belong to the Internet generation, they value social interaction a lot: "The Net Gen often prefers to learn and work in teams. A peer-to-peer approach is common, as well, where students help each other. In fact, Net Geners find peers more credible than teachers when it comes to determining what is worth paying attention to.” (Oblinger \& Oblinger, 2005) Through collaborative learning a student is more prone to become reflective, think critically, and to understand concepts better rather than studying alone (Hew \& Cheung, 2013). Even though there is evidence that students are prone to incorporate their learning through their social networks, Selwyn (2009) points out that such activity should be initiated by students rather than educators. The implications for teaching are that a learning platform needs to provide a socially rich environment in which students can explore their domain of knowledge together with their peers, teachers, and outside experts. Students can play an active role in sharing information and resources with the rest of the class that are of interest to the course, while creating an inter-connected space for communication in which students take the initiative and become more involved (Ventura \& Quero, 2013). While students may have a positive attitude towards to use of social 
network to discuss university work, particularly in the context of group assignments, there can be some resistance to notions of collaboration and collectivism in terms of sharing resources, with students feeling protective over the resources they had identified and allowing them to use social networks on their terms, where its use is student-directed and where they see a defined purpose and relevance (Donlan, 2014).

There is an evidence supported by a large number of empirical studies that social network can serve an important role in the learning environment by supporting student class discussions, collaborative learning, sharing educational resources, extra-curricular resources, and self-managed learning (Manca \& Ranieri, 2013). Studies have shown both positive and negative effects when using Facebook in the learning environment. Facebook can be viewed as useful educational tool and its usage has many advantages. Hurt, Moss, Larson, and Lovelace (2012) compared students perception, attitudes, and educational outcomes using Facebook and conventional LMS, and showed that student group using Facebook reported better educational outcomes than the LMS group (Hurt et al., 2012). On the other hand, other authors found there was no relation between Facebook use and student success in learning (Pasek, More, \& Hargittai, 2009), that there are no differences in GPA between students who did and did not use Facebook (Kolek \& Saunders, 2008), and that even Facebook users can report a lower grade point average (GPA) (Kirschner \& Karpinski, 2010). Junco (2012a) in his study showed that students spend significant amount of time on social networks, checking and engaging in variety of activities (Junco, 2012a), but concluded that time spent on the Facebook is a negative predictor on the GPA (Junco, 2012b).

As such, benefits of usage of social network can be used to further explore its effects in the learning setting, formal or informal. In our research, we use the functionalities of the social network, many of which are alike to Facebook, and integrate them in the learning process, through a custom made social network-like system, social learning environment (SLE). In this work, we investigate in which teaching and learning setting a student will have the most positive attitude towards learning, and what activity will motivate them the most. SLE is an attempt to prove that social networks, and its activities, when used appropriately, can be viewed as manifestation of informal learning and a platform that allows collaboration and effective communication. Courses for distance learning should be created in such a way that will abound in tools that enable discussions, collaborative work, problem solving, and support in learning. This is one of the reasons why we started with a new SLE that would comprise all of this.

\section{Research Design}

For the purpose of this research, a software environment for implementation of computer-based, collaborative learning called Social Learning Environment (SLE) was developed. This tool was designed in such a way to support problem- and project-based learning, while increasing the involvement of students and their interaction with the course instructor. Having students use the existing LMS and Educational Management System (EMS), in order to minimize student confusion with the introduction of a new tool, SLE was designed so that students can access the instructional learning content posted on LMS from the SLE. In a way, SLE is a social network software tool that integrates a collaborative learning platform designed for student and teacher interactions. Furthermore, it has the accessibility to the instructional content on LMS and the features of a social network so that integration with Facebook as an external social 
network is seamless from the learners' perspective. SLE bridges the connection between these technological solutions integrated into a single system.

SLE was designed to test:

1. How social network-like learning environment that is integrated with institution instructional learning design can help improve and increase interaction with students encouraging discussion on topics of interest.

2. How SLE usage can facilitate problem-based and project-based learning through group work and collaboration.

In this research, SLE was used in two teaching models:

1. As a tool for blended learning teaching model.

2. As a tool for online learning teaching.

In both scenarios, the teacher created and posted learning materials as a set of learning objects on LMS. As soon as the learning content is available on LMS, the interactive learning space on SLE is created. The teacher initiates the discussion with questions, assignments, tasks, or problems, which are used for student interaction and the problem-based learning approach. Students would participate in the discussion by either providing an answer, or asking a question to clarify a certain topic. In a blended learning model, the teacher had reading assignment given before the class, while in the class students were grouped and worked on solving different problems which were posted on SLE. In the online learning model, students were given questions for discussion and assigned different problems to work on SLE. Both teachers and students can initiate discussions or problems on SLE with an additional option to share this as an announcement on the Facebook.

\section{SLE-Based Teaching and Learning Activities}

This section describes possible SLE usage scenarios in different types of classrooms. Even though SLE is designed to provide flexible teaching, its foundation lies on the problem- and project-based learning, hence the scenarios that are presented here support these forms. The flexibility given by SLE lies in the fact that the student is given an option to start learning either by accessing the instructional design first, through LMS, or by accessing posted assignments on SLE. Two models of activities are described: teaching activities that include creation of learning content and learning activities as seen by students.

\section{Model of Teaching Activities}

When using SLE, teaching activities include not only activities that take place in-class, but also the preparation of learning content and planning of in-class, and/or online active learning strategies. The model of teaching activities is presented in Figure 1. Instructional teaching material is created in the forms of LOs, in order to have better flexibility in teaching design. Each LOs is created as a modular unit, 
presenting a good base for problem and task assignment. Once the content and self-assessments are created, they are published. Publishing of a lesson on LMS automatically creates interactive learning space in SLE, where each lesson has its own discussion space. Before the announcement about lesson creation is published, the teacher can create initial problems, tasks, discussion questions, and/or resources that are posted on SLE. It is left to the instructor to decide on the structure and timing of the activities posted on SLE. These could be posted for a discussion prior to class, or even for the usage during the class time. Initial interactive space created on SLE is shown in Figure 2.

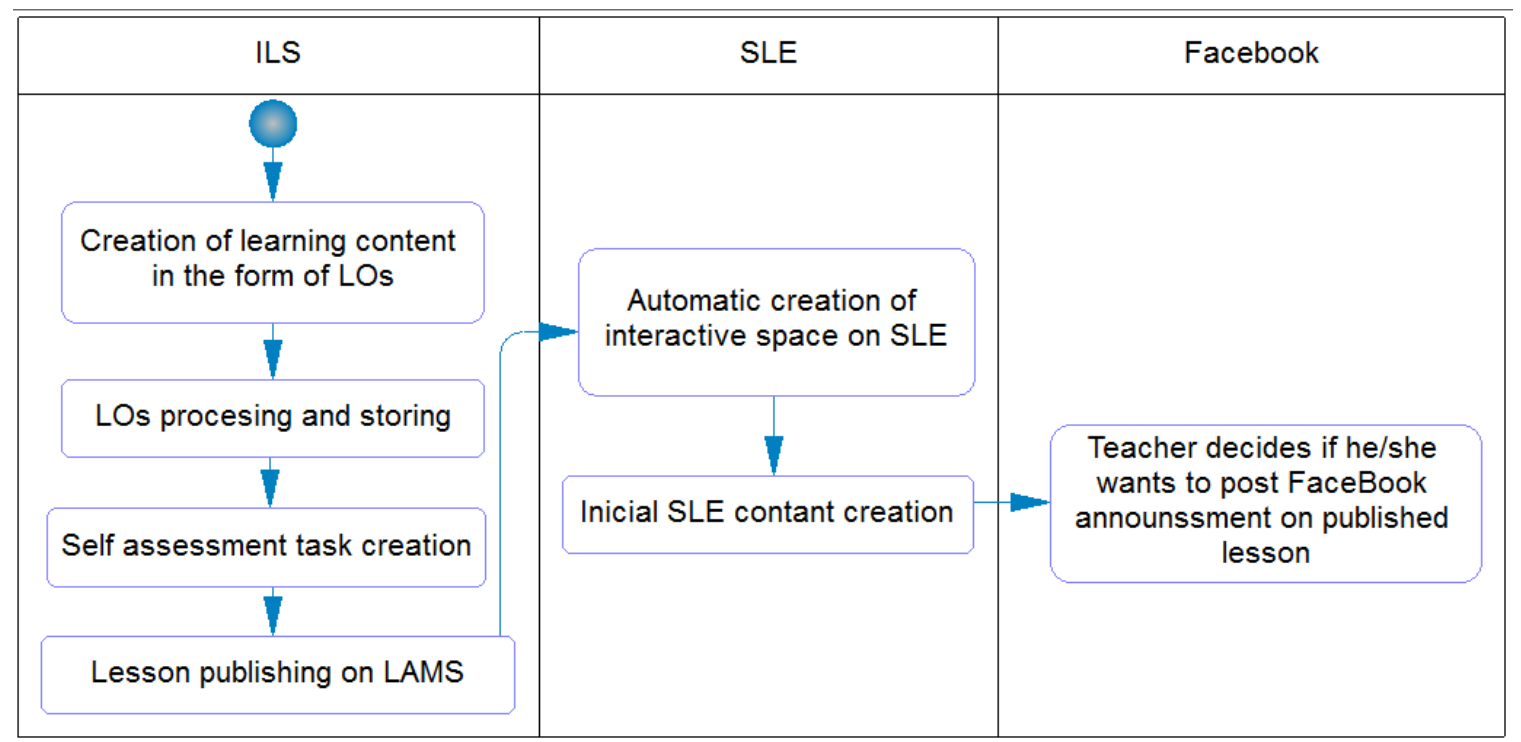

Figure 1. Model of teaching activities.

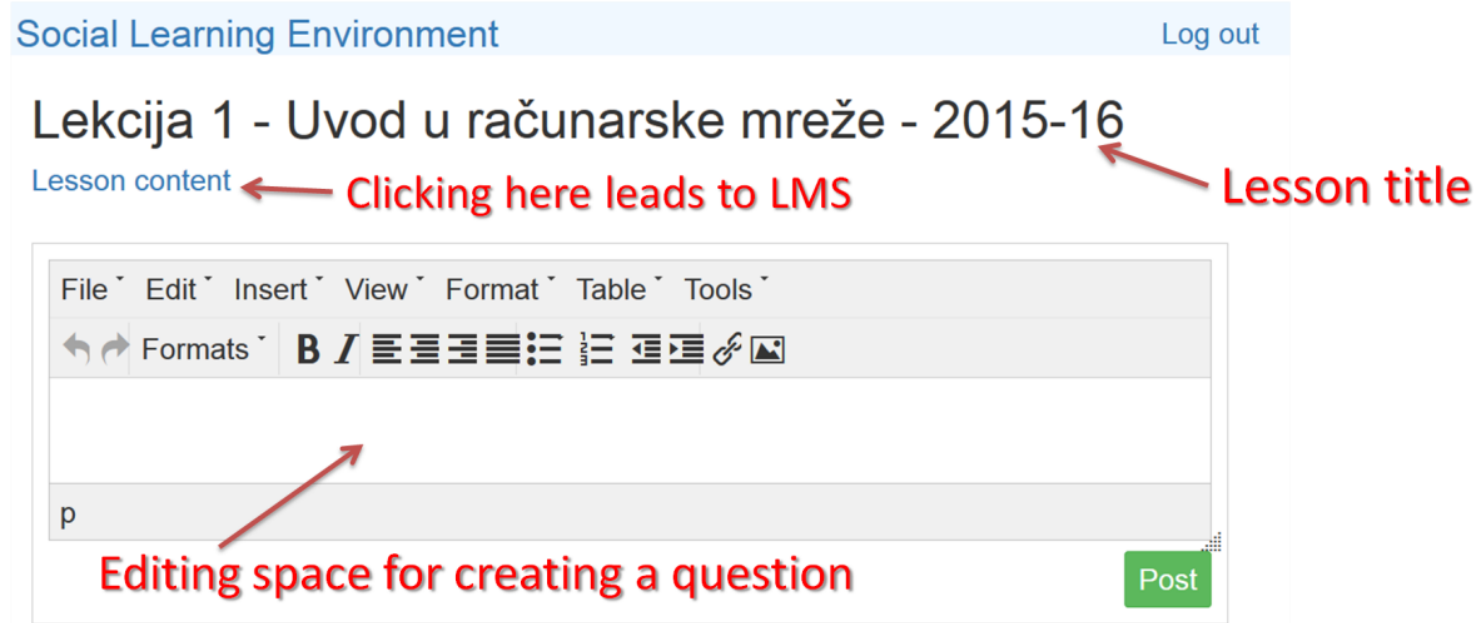

Figure 2. Initial interactive learning space in SLE. 


\section{Model of Learning Activities}

SLE provides an option to students to either start learning through lesson content or to start by solving problems and tasks initially posted by the instructor. Once the lesson content is created and published, student receives an announcement that the activity on SLE is available. The learning activities on SLE include the following:

1. The student accesses the SLE and chooses whether he/she wants to access the learning content first or the assigned problems in the interactive space in SLE.

2. If the student decides to read learning content, he/she is prompted to go through the sequence of assigned LOs for that lesson.

3. If the student decides to attempt assigned problems and tasks on SLE, he/she can either partake in the discussion and problem solving, or he/she can share useful resources needed for successful completion of a problem by the rest of the group.

4. Students are encouraged to share resources or even post their own problems or tasks relating to that lesson.

5. The teacher serves as a moderator throughout this learning process, and can post additional tasks and resources needed to gauge students' progress and continuation of their engagement.

It should be noted here that previously stated steps are not necessarily sequential and could occur in parallel, or in different order. The student can at any time access learning content posted on LMS.

The groups' discussions and problem solving can be conducted in different manners. Here, as an example, we provide two scenarios that were used during the evaluation of SLE teaching and learning approach.

\section{Scenario 1 - Blended Classroom Model}

Our blended classroom model was inspired by the active learning strategies. In this model, students initially read their instructional learning material at their own pace. Students were given a set of questions relating to these materials, and answered these questions prior to coming to class. Student answers were used to help the instructor to gain an overview of students' progress, understandings, and misconceptions about the learning content. The beginning of the class would start with addressing these misconceptions in the discussion format, and if necessary, a mini lecture on the complex or misunderstood concepts was given. By reading the learning content prior to class, students were able to actively engage in this discussion. Once the instructional material was discussed, students were organized in groups, and were given a set of problems to solve. Problem assignments were posted on SLE interactive space, and students posted their solution as reply to original post. Once the group solved their problems, their next assignment was to go through the problem of another group and to evaluate whether their problem was solved correctly (in-class peer assessments). In-class agreement, between teacher and students, was to "like" a solution if the problem was correct, or post a comment if there were any errors. Students were also encouraged to post additional problems they liked and to share them with the class. At any moment, students were able to access their 
learning content for that particular lesson through SLE. Figure 3 represents one of the problems posted for the group activities in the Computer Networks class, where the task was to determine a routing table for the simple network.

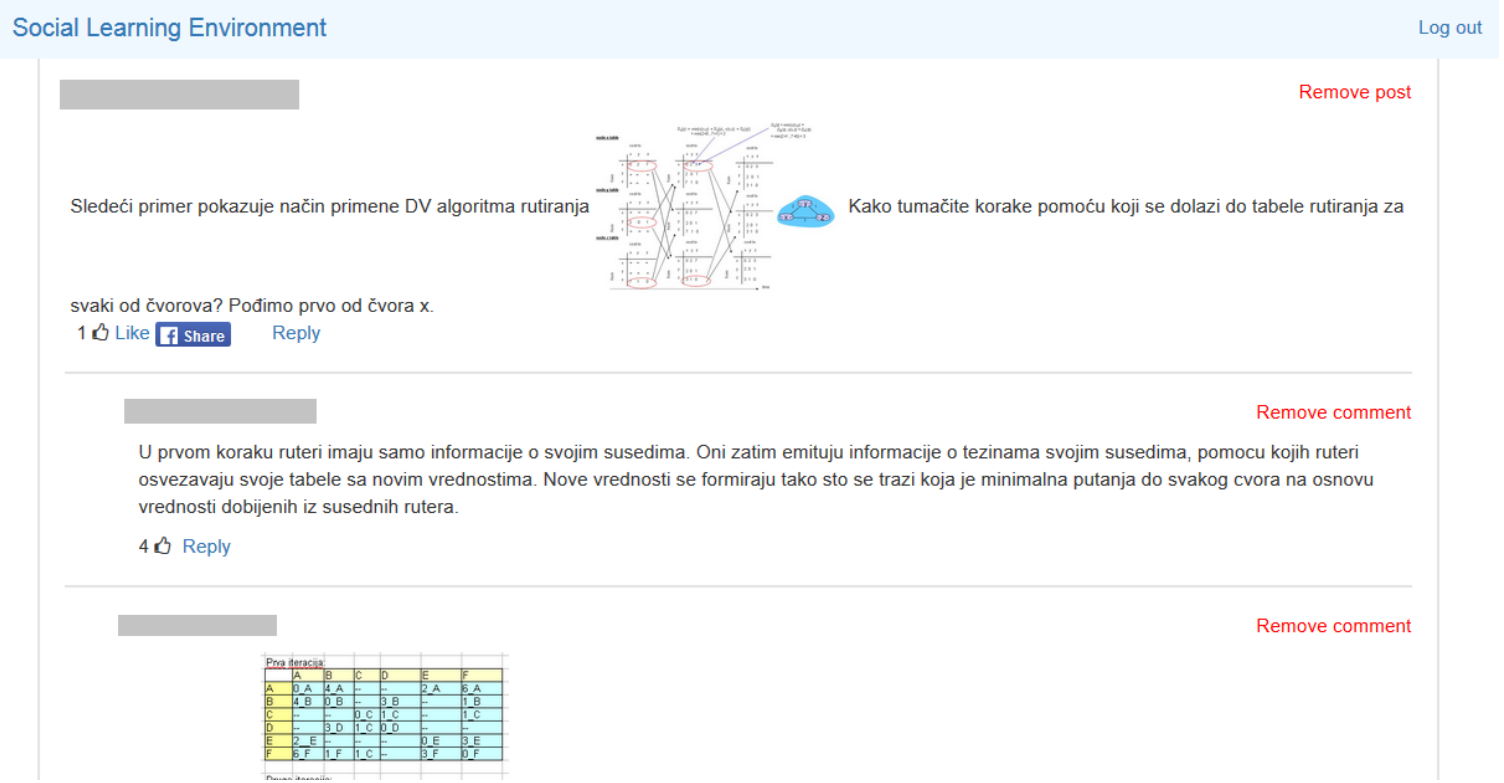

Figure 3. Example of a solved and discussed problem by a group of students in a blended classroom model.

\section{Scenario 2 - Online Classroom Model}

Once the lesson is published on LMS and the SLE interactive space is created, the learning process begins in the online classroom model of SLE usage. Just like in the blended learning model, students have a choice to either access instructional learning material first, or to access activities on SLE. In both cases, students collaborate directly with the instructor and other students on SLE, they use resources that are posted by other participants in the learning process, answer and solve tasks and problems, and take part in the discussion. The social network-like functionalities in SLE, such as "like" and "share" options, are there to encourage students to assess their peers' work. The instructor role in the collaboration is to gain an overview of students' progress and to moderate students' discussions. Based on the students' post, instructors can adjust tasks, problems, and additional resources in order to improve students' current knowledge level, and moreover, to keep students engaged in their online learning process. It can be said that in this model, problem solving and inquiry based learning through the search for the solution of the problem is an integral component of the learning process. Figure 4 displays a segment of one of the discussions relating to determining an SQL quarry in the Database course. 
Izvršte redizajniranje predhodno urađenog konceptualnog modela tako što ćete umesto veze 1:M između entiteta ARANZMAN i MENI stavite vezu M:M. nakon promene kardinalnosti veze napišite SQL rečenice kojima se može izvršiti migracija podataka.

10 Share Reply

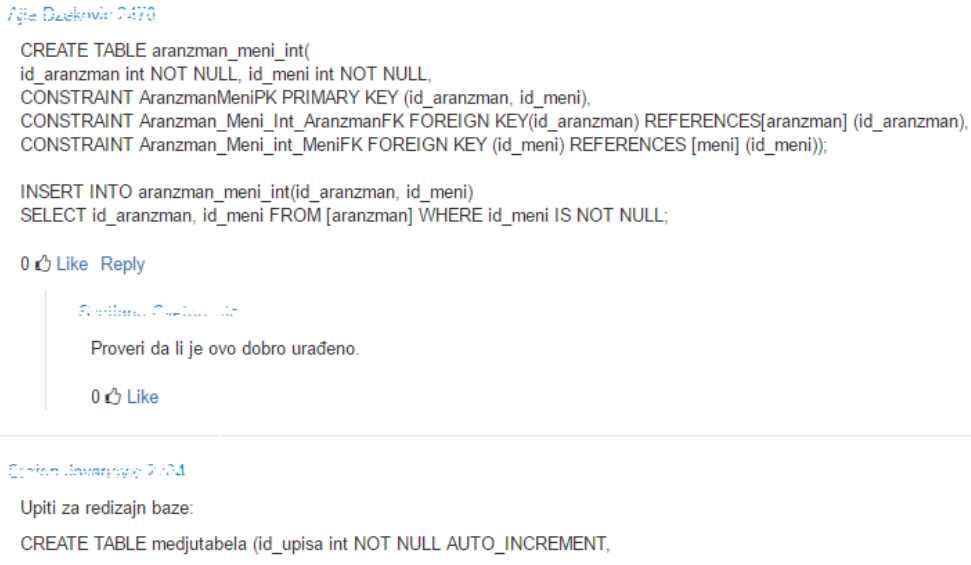

Figure 4. Example of a solved and discussed problem by a group of students in an online classroom model.

\section{Platform Architecture}

The entire integrated system includes: Institutional Learning System (ILS), Educational Management System (EMS), Social Learning Environment (SLE), and Facebook (Figure 5). As each system represents individual software component, each system is integrated by its set of web services, allowing for a smooth and seamless communication between the systems. This feature is important, as it avoids burdening learner with more information, passwords, and multiple logins. EMS, SLE, and ILS are integrated with a singlesign-on feature, allowing a learner to have a feeling of a single system.

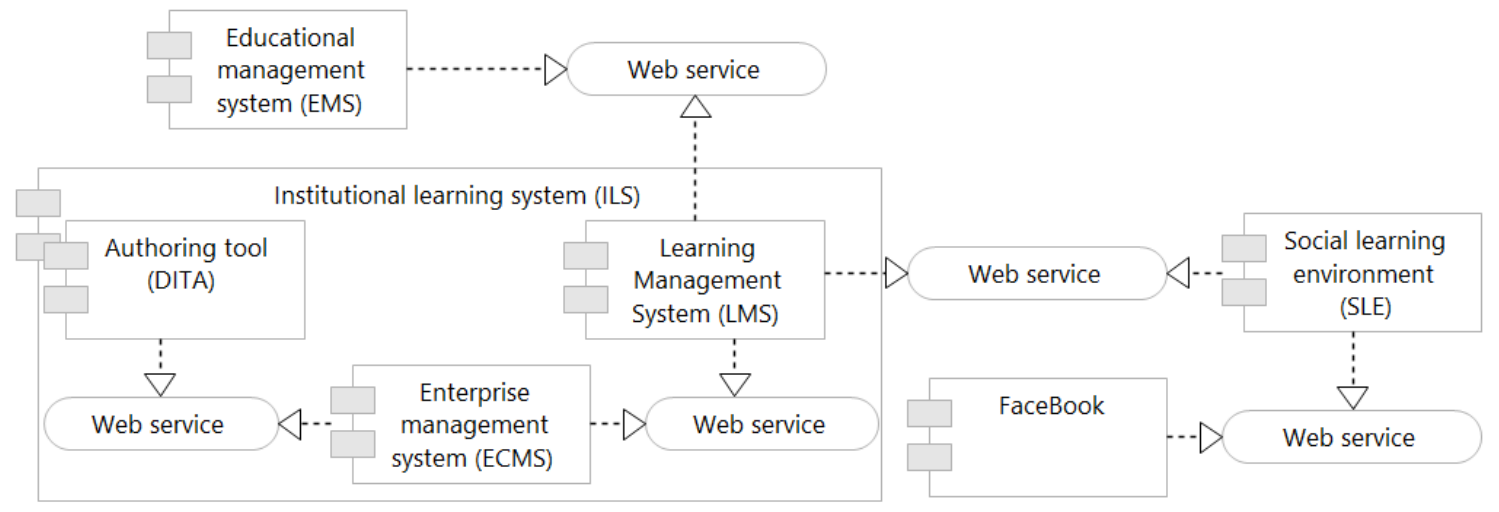

Figure 5. Platform architecture of the integrated systems. 
The main functionality of the ILS is to allow creation and storage of the learning content, which is designated for the instructional design. ILS represents already existing institutional system that is not prone to changes and it lacks flexibility. In this architecture, ILS is composed of three technological solutions: Authoring tool, Enterprise management system (ECMS), and Learning Management System (LMS). In our work, the complex structure of ILS is the result of the need that ILS should support implementation and presentation of learning materials through series of learning objects (LOs). LOs modularity allows for implementation of adaptive and collaborative teaching models, as each LO can be individually discussed and elaborated through interaction between teacher and students.

Each of the presented subsystems that constitute ILS has its own purpose. The Authoring tool allows creation of LOs and structuring LOs content according to a structured ontology (in this work DITA ontology). ECMS primary serves as a repository of LOs, but ECMS also enables LOs to be arranged as appropriate sequences, and published to LMS. Each LOs' sequence, prepared in ECMS and published on LMS, presents a lesson or course. For the purpose of this work as LMS, Learning Activities Management System (LAMS) was used.

LAMS does not only allow LOs' sequences to be published, but it also provides graded and non-graded assessment activities. There are two types of LAMS's activities: student self-assessments (tests containing open questions, true/false, single select or multiple answer type questions, task), and activities that enable communication and interaction (chat, wiki, forum, etc.). Even though such systems provide great tools in an online teaching, they have certain shortcomings. Shortcomings are a result of lack of flexibility of LAMS. For instance, students cannot directly collaborate with their peers and teachers during solving their tasks or assignments. In other words, these systems allow for collaborative and interactive learning to some extent, but there is a need for their improvement.

EMS supports university's business processes. It is based on the relational database containing data about students, their exams, and grades, courses from academic major curriculum, teachers, and teacher course assignments. The integration of EMS with LMS enables that all necessary information about students, teachers, and courses are provided and shared with LMS.

In order to make student interaction and collaboration more effective and to fully enable collaborative education, the social networks are added in learning platform. The exploitation of social networks is an attempt to enrich currently used technologies with an innovative, value added components, which can be used to increase student motivation, interaction, and satisfaction. In this architecture, social networks are not directly integrated with LMS. The integration is realized by adding new a SLE component that accesses both LMS and Facebook. Every time a lesson and its learning activities are published on LMS, the same content and structure is imported from LMS and published on SLE. In SLE, the instructor can manage lesson/course activities by posting discussions, tasks, and problems relating to the published material, or by sharing additional learning material that are used for continuous interaction with students. Any announcements about new learning events in SLE and posted comments can be shared on Facebook. 


\section{Methodology}

The evaluation of SLE was conducted in four different courses, for the duration of a month. This evaluation included 72 students. After one month of SLE exploitation, students were asked to rank satisfaction about SLE usage through a survey. Each response to survey question was scaled based on the 5-point Likert scale with the following approach: 1-very dissatisfied, 2-dissatisfied, 3-neither satisfied nor dissatisfied, 4satisfied, 5-very satisfied. Fifty-five participated in providing the feedback through the designed questionnaire. Out of 55 students, 39 (70.9\%) were male and 16 (29.1\%) were female.

The analysis of research questions was specially focused on analyzing whether the students have been satisfied with SLE as a component that:

i. Influence the student learning and motivate them to further research the lesson topic by sharing the resources and collaborating with peers.

ii. Increase student interaction and communication with teacher and peers.

The intent was to use this analysis to plan future improvements of the SLE components, both in the aspect of teaching and learning design, as well as the functionalities offered by the SLE as a software tool. The integration and implementation of SLE were examined by analyzing the following:

- How much students have been satisfied with SLE in mastering the learning content and in establishing better communications with course instructor, teaching assistant, and peers.

- If student have been satisfied with SLE usefulness for sharing additional resources during the problems solving.

- If student have been satisfied with SLE as an effective component for accessing learning material on LMS.

- If students have been satisfied with SLE learning experience and if they would appreciate using SLE in other courses.

In order to be able to address future improvements and better predict which parameters will increase collaboration, communication, and effectively improve learning experience for students, dependence between all parameters was analyzed using Spearman correlation method. In this analysis we have taken into account positive correlation, when $\mathrm{r}$ is greater than 0.5 .

\section{Results}

The analyses of results are divided into two parts: (i) the analysis of student usage and satisfaction with the SLE, and (ii) the analysis of correlation between the questions about students' satisfaction in order to address the future improvements of SLE. 


\section{Analysis of Student Satisfaction with the SLE}

Based on the average marks given on answers shown in Table 1, students were most positive about wanting to be alerted when new activity was available; however, they preferred notification via email, 3.49 \pm 1.59 (with the median 4.00) and not by Facebook, 2.36 \pm 1.66 (with the median 1.00). Furthermore, students did not show a high level of interest on further integrating SLE with Facebook, $2.60 \pm 1.64$ (with median 2.00).

Students' comments in the survey suggested that posting individual push notifications to their private Facebook walls may not be very effective. It is our assumption that they view their wall as a private space. However, they suggested that creation of a Facebook page for the course may be something that they are prone to: "Do not use the Facebook. If you have Facebook, just have on group that will make announcements."

It can be concluded that future improvements of SLE should not emphasize Facebook notifications, but keep this as an optional functionality that the instructor can use to post announcement to the Facebook dedicated page for that particular course.

Low satisfaction with Facebook integration was a surprise for the faculty, but what was even more interesting was the additional comments students added to their survey answers, stating that they would like to have a mobile application that would give push notifications and alert them about the new content and SLE posts: "I think it would be ideal to create mobile application, which would include push notifications when new problem is posted or when a professor or teaching assistant comments on our answer."

Table 1

Survey Questions for Evaluation of Students'Survey Answers

\begin{tabular}{|l|r|r|r|}
\hline Questions & $\mathrm{X} \pm$ & $\mathrm{SD}$ & $\mathrm{Med}$ \\
\hline $\begin{array}{l}\text { Q1. How much have activities on SLE helped you with mastering the } \\
\text { learning content? }\end{array}$ & $3.22 \pm$ & 1.12 & 3.00 \\
\hline $\begin{array}{l}\text { Q2. How much have activities on SLE helped you in establishing better } \\
\text { communications with your course instructor? }\end{array}$ & $3.40 \pm$ & 1.26 & 3.00 \\
\hline $\begin{array}{l}\text { Q3. How much have activities on SLE helped you in establishing better } \\
\text { communications with teaching assistant? }\end{array}$ & $2.65 \pm$ & 1.31 & 3.00 \\
\hline $\begin{array}{l}\text { Q4. How much have activities on SLE helped you in establishing better } \\
\text { communications with your peers? }\end{array}$ & $3.16 \pm$ & 1.32 & 3.00 \\
\hline $\begin{array}{l}\text { Q5. Would you like to use SLE in other courses? } \\
\text { Q6. Do you think it would be useful to use SLE throughout the } \\
\text { semester in the course? }\end{array}$ & $3.18 \pm$ & 1.49 & 3.00 \\
\hline $\begin{array}{l}\text { Q7. How much have you shared additional resources with your peers } \\
\text { on SLE, which helped you with solving problems? }\end{array}$ & $3.18 \pm$ & 1.39 & 3.00 \\
\hline Q8. Have you used lessons on LAMS while solving problems on SLE? & $3.24 \pm$ & 1.20 & 3.00 \\
\hline
\end{tabular}




\begin{tabular}{|l|r|r|r|}
\hline $\begin{array}{l}\text { Q9. Have you used other resources more, than the ones on LAMS, } \\
\text { while working on solving problems on SLE? }\end{array}$ & $3.15 \pm$ & 1.28 & 3.00 \\
\hline $\begin{array}{l}\text { Q10. Do you think it will be useful for SLE to send you email } \\
\text { announcement that new activity is available? }\end{array}$ & $3.49 \pm$ & 1.59 & 4.00 \\
\hline $\begin{array}{l}\text { Q11. Do you think it will be useful for SLE to send you a Facebook } \\
\text { notification that new activity is available? }\end{array}$ & $2.36 \pm$ & 1.66 & 1.00 \\
\hline $\begin{array}{l}\text { Q12. Do you think that further integration with Facebook would help } \\
\text { you to increase interaction with your peers? }\end{array}$ & $2.60 \pm$ & 1.64 & 2.00 \\
\hline
\end{tabular}

Additional comments suggested that even though students responded positively to SLE, they were also open to use SLE in other courses as well: "It would be very useful to use SLE throughout the entire year and in more courses."

Moreover, students had general feedback of the functionalities and user interface of SLE: "Allow for deletion and editing of posted answers," "Teachers post should be darker, so it can be noticed easier," and "It should allow for sorting of teacher and student messages, or at least open a new thread for new assignment. All in all, it is great."

Additional comments suggested that students find SLE useful and motivating in their group assignments, which can lead to a conclusion that SLE can be used as an effective tool for group collaboration: "SLE is useful for problem assignment and to assign group to different problems to solve" and "I think that this system should not be a requirement, but a tool of great help in the interaction between teacher, teaching assistant and students."

This feature should be further analyzed in future research and team collaboration in online social environment should be further explored.

\section{Analysis of Correlation between the Questions about Students' Satisfaction}

In order to be able to address the future improvements and predict future results, correlation between the survey questions was analyzed. As shown in Table 2, it is evident that a statistically significant positive correlation exists between most questions. The degree of correlation was classified as follows: small (from 0.10 to 0.29 ), moderate (from 0.30 to 0.49 ), and high (from 0.50 to 1 ).

The results in the Table 2 show that students who consider that activities on SLE helped them with mastering the learning content also think that activities on SLE helped them in establishing better communications with their course instructors and their peers (Q1 and Q2, p<0.001; Q1 and Q4, p<0.001). Similar to the previous conclusion, students who think that SLE helped them in establishing better communications with course instructor, also consider that SLE lead to a better communication with their peers (Q2 and Q4, p<0.001). Students who were satisfied with learning activities in SLE, were also satisfied with better overall communications with all participants in SLE, which lead to their preference to continue on using SLE in other courses. This can be seen from the high correlation between questions 1-6 (Q1 and Q5, p<0.001; Q1 and Q6, p<0.001; Q2 and Q5, p<0.001; Q2 and Q6, p<0.001; Q3 and Q5, p<0.001; Q4 and Q5, $\mathrm{p}<0.001$; and $\mathrm{Q} 4$ and $\mathrm{Q} 6, \mathrm{p}<0.001)$. 
Students who have a positive opinion about the idea of using SLE in other courses throughout the semester also consider that it would be useful for SLE to send them email announcement when new activity is available (Q5 and Q10, p<0.001; Q6 and Q10, p<0.001), which goes in line with students requirement to have push notifications either by email or mobile application. On the other hand, correlation between Q8 and Q12, p<0.001, as well as Q11 and Q12, p<0.001, can present one more confirmation about low student satisfaction with Facebook integration. These results cannot conclusively rule out the usage of Facebook in the learning process. This may indicate that students are not yet aware of the Facebook possibilities in the learning process, as the evaluation of SLE was not conducted the entire semester. Also, by setting clear rules of Facebook usage and announcement, and setting up class culture with using all of its options may increase student satisfaction and utilize full potential of using Facebook in the learning process. However, this should be introduced carefully, as the evaluation shows that Facebook private walls may be viewed as private space, and not additional classroom resource. Further usage of Facebook in SLE learning activities should be further analyzed in order to be able to conclude of its effectiveness in this learning environment.

What remains unclear from this analysis is the level of usage of instructional learning material on LMS and its correlation with level and communication experience of students. Even though previous analysis showed that students have marked high their LAMS learning materials and other resources, it should be further analyzed how these materials contribute to the learning process, and if their inclusion in SLE should be modified.

Table 2

Correlation between the Survey Questions

\begin{tabular}{|c|c|c|c|c|c|c|c|c|c|c|c|c|c|}
\hline & & Q1. & Q2. & Q3. & Q4. & Q5. & Q6. & Q7. & Q8. & Q9. & Q10. & Q11. & Q12. \\
\hline Q1 & $\begin{array}{l}\text { Correlation } \\
\text { Coefficient }\end{array}$ & 1.000 & .765 & .418 & .663 & .669 & .749 & .594 & .307 & .260 & .464 & .138 & .290 \\
\hline Q2 & $\begin{array}{l}\text { Correlation } \\
\text { Coefficient }\end{array}$ & $\begin{array}{l}.765 \\
* * *\end{array}$ & 1.000 & .413 & .600 & .583 & .701 & .483 & 279 & .184 & .393 & 179 & .187 \\
\hline Q3 & $\begin{array}{l}\text { Correlation } \\
\text { Coefficient }\end{array}$ & .418 & .413 & 1.000 & .681 & .508 & .314 & .417 & .481 & .251 & .336 & .457 & . 452 \\
\hline Q4 & $\begin{array}{l}\text { Correlation } \\
\text { Coefficient }\end{array}$ & .663 & $\begin{array}{l}.600 \\
* * *\end{array}$ & $\begin{array}{l}. \mathbf{6 8 1} \\
* * *\end{array}$ & 1.000 & .607 & .535 & .679 & .403 & .341 & .455. & 244 & .262 \\
\hline Q5 & $\begin{array}{l}\text { Correlation } \\
\text { Coefficient }\end{array}$ & $\begin{array}{l}.669 \\
* * *\end{array}$ & $\begin{array}{c}.583 \\
* * *\end{array}$ & $\begin{array}{l}.508 \\
.5 * *\end{array}$ & .607 & 1.000 & .797 & .362 & .435 & .202 & .514 & .274 & .367 \\
\hline Q6 & $\begin{array}{l}\text { Correlation } \\
\text { Coefficient }\end{array}$ & $\begin{array}{l}.749 \\
* * *\end{array}$ & $\begin{array}{l}.701 \\
* * *\end{array}$ & $.314^{*}$ & $\underset{* * *}{.535}$ & $\begin{array}{l}.797 \\
* * *\end{array}$ & 1.000 & .320 & .324 & .150 & .503 & .229 & .282 \\
\hline Q7 & $\begin{array}{l}\text { Correlation } \\
\text { Coefficient }\end{array}$ & $\begin{array}{r}.594 \\
* * *\end{array}$ & .483 & $.417^{* * *}$ & $\begin{array}{l}.679 \\
* * *\end{array}$ & .362 & .320 & 1.000 & .266 & .331 & .304 & .161 & .171 \\
\hline Q8 & $\begin{array}{l}\text { Correlation } \\
\text { Coefficient }\end{array}$ & .307 & .279 & .481 & .403 & .435 & $\cdot 324$ & .266 & 1.000 & .243 & .257 & .415 & .529 \\
\hline Q9 & $\begin{array}{l}\text { Correlation } \\
\text { Coefficient }\end{array}$ & .260 & .184 & .251 & .341 & .202 & .150 & .331 & .243 & 1.000 & .149 & .168 & .254 \\
\hline
\end{tabular}




\begin{tabular}{|c|c|c|c|c|c|c|c|c|c|c|c|c|c|}
\hline Q10 & $\begin{array}{l}\text { Correlation } \\
\text { Coefficient }\end{array}$ & .464 & .393 & .336 & .455 & $\begin{array}{r}.514 \\
* * *\end{array}$ & $\underset{* * *}{.503}$ & .304 & .257 & .149 & 1.000 & .371 & .372 \\
\hline Q11 & $\begin{array}{l}\text { Correlation } \\
\text { Coefficient }\end{array}$ & .138 & .179 & $\begin{array}{l}.457 \\
* * *\end{array}$ & .244 & $\begin{array}{c}.274 \\
*\end{array}$ & .229 & .161 & .415 & .168 & $\stackrel{371}{* *}$ & 1.000 & .811 \\
\hline Q12 & $\begin{array}{l}\text { Correlation } \\
\text { Coefficient }\end{array}$ & .290 & .187 & .452 & .262 & .367 & $\begin{array}{c}.282 \\
*\end{array}$ & .171 & $\begin{array}{r}.529 \\
* * *\end{array}$ & .254 & 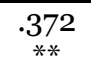 & $\underset{* * *}{. \mathbf{8 1 1}}$ & 1.000 \\
\hline
\end{tabular}

${ }^{* * *}-p<0.0011^{* *}-p<0.01,{ }^{*}-p<0.05$

\section{Conclusions and Future Work}

This paper presented the usage of the Social Learning Environment tool, which was designed in line with the concepts of computer supported collaborative learning approach and socio-constructivist theory. Even though SLE has a feel of a social network, it was the intent of this tool to serve as a connecting interactive learning space for increasing the communication between students and the teacher, and to motivate students for active learning through collaborative problem solving tasks. SLE presents an attempt of integration social networks functionalities in the learning formats, but under control of appropriate pedagogical methods. As such platform, SLE is not meant to substitute LMS and instructional teaching, but rather to increase the interaction and collaboration. Through this interaction and collaboration, the analyses have shown that the quality of learning activities on SLE lead to higher student satisfaction with communication with teachers and their peers, but also that this collaboration contributed to their better understanding of the course topics. Through a presented sample scenarios, it was presented that SLE gives teachers greater flexibility, and that they can through analysis of students' work follow up on their progress and adjust their tasks and discussions in order to maintain their interest and to clarify misconceptions.

Even though SLE provided an option for students to share their posts on Facebook, and for Facebook to send them announcements about new posts, the analyses showed that students had a low interest in further integration of SLE and its connection with Facebook. However, these results cannot conclusively exclude Facebook from future use with SLE, but should be further analyzed and examined. Setting up certain rules and methodology for how Facebook should be used in different class scenario, may lead to different results, as Facebook was only moderately used with the early adoption group. This work explores usage of Facebook in formal or informal learning setting; however, the results do not point out on the exact response about Facebook' usefulness. In order to more precisely define the Facebook's role and compare Facebook usage with other tools for communication and collaboration, future work, and improvements of SLE should focus on functionalities improvements that can include:

- Integration of the graphical user interface of ILS, SLE, and EMS.

- Improvement of the graphical user interface so that teacher and student posts can be easily identified, differentiated, and navigated.

- Development of the announcement system which may include email announcements, mobile announcements, and/or Facebook announcements for a dedicated Facebook course page. 
As the few student comments begin to indicate, a qualitative approach such as focus groups with staff and students using the new tool should be included in future analysis and that would provide a much richer picture. Also, as it remains unclear how student satisfaction with learning materials on LMS related to their learning process, future work should analyze this relation and identify how to better include instructional learning material with SLE activities. As LAMS allows for learning materials to be presented as the sequence of LOs, future work should address how to utilize individual LOs with SLE activities.

\section{Acknowledgment}

The work presented here was supported by the Serbian Ministry of Education, Science and Technological Development.

\section{References}

Aydin, S. (2012). A review of research on Facebook as an educational. Educational Technology Research and Development, 6o(6), 1093-1106. doi:10.1007/s11423-012-9260-7

Bruner, J. (1996). The culture of education. Cambridge, Massachusetts: Harvard University Press.

Christudason, A. (2003). Peer learning. Successful Learning, (37). Retrieved from http://www.cdtl.nus.edu.sg/success/sl37.htm

Dabbagh, N., \& Kitsantas, A. (2012). Personal learning environments, social media, and self-regulated learning: A natural formula for connecting formal and informal learning. The Internet and Higher Education, 15(1), 3-8.

Donlan, L. (2014). Exploring the views of students on the use of Facebook in university teaching and learning. Journal of Further and Higher Education, 38(4), 572-588.

Fagen, A., Crouch, C., \& Mazur, E. (2002). Peer instruction: Results from a range of classrooms. The Physics Teacher, 40, 206-209.

Hew, K. F., \& Cheung, W. S. (2013). Audio-based versus text-based asynchronous online discussion: Two case studies. Instructional Sciences, 41, 365-380. doi:10.1007/s11251-008-9087-0

Hurt, N. E., Moss, G. S., Larson, L., \& Lovelace, M. (2012). The “Facebook” effect: College students' perceptions of online discussions in the age of social networking. International Journal for the Scholarship of Teaching and Learning, 6(2), 1-24.

Joordens, M., Chandrasekaran, S., Stojcevski, A., \& Littlefair, G. (2012). The process of design based learning: A students' perspective. Proceedings of the 2012 AAEE Conference, (pp. 927-934). Melbourne, Victoria. 
Junco, R. (2012a). The relationship between frequency of Facebook use, participation in Facebook activities, and student engagement. Computers \& Education, 58(1), 162-171.

Junco, R. (2012b). Too much face and not enough books: The relationship between multiple indices of Facebook use and academic performance. Computers in Human Behavior, 28(1), 187-198.

Kehrwald, B. (2008). Understanding social presence in text-based online learning environments. Distance Education, 29(1), 89-106. doi:10.1080/01587910802004860

Kirschner, P. A., \& Karpinski, A. C. (2010). Facebook and academic performance. Computers in Human Behavior, 26(6), 1237-1245.

Kolek, E. A., \& Saunders, D. (2008). Online disclosure: An empirical examination of undergraduate Facebook profiles. NASPA Journal, 45(1), 1-25.

Kolmos, A. (1996). Reflections on project work and problem-based learning. European Journal of Engineering Education, 21(2), 141-148.

Koschmann, T. (1996). Paradigm shifts and instructional technology: An introduction. In CSCL: Theory and practice of an emerging paradigm (pp. 1-23). Mahwah, NJ: Lawrence Erlbaum Associates.

Kreijns, K., Kirschner, P. A., \& Jochems, W. (2003). Identifying the pitfalls for social interaction in computer-supported collaborative learning environments: A review of the research. Computers in Human Behavior, 19(3), 335-353.

Lewis, S., Pea, R., \& Rosen, J. (2010). Beyond participation to co-creation of meaning: Mobile social media in generative learning communities. Social Science Information, 49(3), 351-369.

Manca, S., \& Ranieri, M. (2013). Is it a tool suitable for learning? A critical review of the literature on Facebook as a technology-enhanced learning environment. Journal of Computer Assisted Learning, 29(6), 487-504.

McLoughlin, C., \& Lee, M. J. (2010). Personalised and self regulated learning in the Web 2.o era: International exemplars of innovative pedagogy using social software. Australasian Journal of Educational Technology, 26(1).

Oblinger, D. G., \& Oblinger, J. L. (2005). Is it age or IT: First steps toward understanding the net generation. In D. G. Oblinger, \& J. L. Oblinger (Eds.), Educating the net generation (Chapter 2). EDUCAUSE. Retrieved from https://net.educause.edu/ir/library/pdf/pub7101.pdf

Pasek, J., More, E., \& Hargittai, E. (2009). Facebook and academic performance: Reconciling a media sensation with data. First Monday, 14(5).

Richardson, J. C., \& Swan, K. (2003). Examining social presence in online courses in relations to students' perceived learning and satisfaction. Journal of Asynchronous Learning Networks, 7(1), 68-88. 
Roblyer, M. D., McDaniel, M., Webb, M., Herman, J., \& Witty, J. V. (2010). Findings on Facebook in higher education: A comparison of college faculty and student uses and perceptions of social networking sites. The Internet and Higher Education, 13(3), 134-140.

Savery, J. R., \& Duffy, T. M. (1995). Problem based learning: An instructional model and its constructivist framework. Educational Technology, 35(5), 31-38.

Selwyn, N. (2009). Faceworking: Exploring students' education-related use of Facebook. Learning, Media and Technology, 34(3), 157-174.

Swan, K., \& Shih, L. F. (2005). On the nature and development of social presence in online course discussions. Journal of Asynchronous Learning Networks, 9(3), 115-136.

Tess, P. A. (2013). The role of social media in higher education classes (real and virtual)-A literature review. Computers in Human Behavior, 29(5), A60-A68.

Turpen, C., \& Finkelstein, N. (2010). The construction of different classroom norms during peer instruction: Students perceive differences. Physical Review Special Topics - Physics Education Research, 6(020123-1). doi:10.1103/PhysRevSTPER.6.020123

Väljataga, T. P., \& Tammets, K. (2011). Considering students' perspectives on personal and distributed learning environments in course design. In M. J. Lee, \& C. McLoughlin (Eds.), Web 2.o-based elearning: Applying social informatics for tertiary teaching (pp. 85-107). Hershey, PA: IGI Global.

Ventura, R., \& Quero, M. J. (2013). Using Facebook in university teaching: A practical case study. Procedia-Social and Behavioral Sciences(83), 1032 - 1038. doi:10.1016/j.sbspro.2013.06.192

Vygotsky, L. S. (1987). Thinking and speech (N. Minick, Trans.). In R. W. Rieber \& A. S. Carton (Eds.), The collected works of L. S. Vygotsky: Vol. 1. Problems of general psychology (pp. 39-285). New York: Plenum Press. (Original work published 1934)

Wang, Q. (2009). Design and evaluation of a collaborative learning environment. Computers \& Education, 53(4), 1138-1146.

Wenglinsky, H. (2005). Technology and achievement: The bottom line. Educational Leadership, 63(4), 29-32.

Zornić, D., \& Hasanović, E. (2011). Uloga interakcije u online učenju [The Role of Interaction in Online Learning]. Elektronski zbornik radova sa međunarodne konferencije YUINFO 2011. Retrieved from http://www.e-drustvo.org/proceedings/YuInfo2011/html/pdf/229.pdf 
The Effects of Integrating Social Learning Environment with Online Learning Raspopovic, Cvetanovic, Medan, and Ljubojevic

Athabasca University

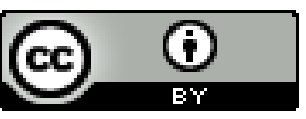

160 